\title{
Instrumentos musicales paleolíticos: la flauta magdaleniense de la Cueva de la Güelga (Asturias)
}

\author{
MaRio MENÉndez ${ }^{*}$ Y EduARdo García ${ }^{* *}$
}

\begin{abstract}
RESUMEN
Presentamos un tubo de hueso largo de ave, decorado con series de incisiones lineales. Esta pieza pertenece al Magdaleniense inferior de la Cueva de la Güelga. Los paralelos indican que este tema es repetitivo en esa fase paleolifica en el Cantábrico, por lo que pudiera constituir un motivo característico. Su interpretación como flauta nos permite una serie de reflexiones sobre los instrumentos musicales paleoliticos en general y sobre este tipo de piezas en particular.
\end{abstract}

\section{PALABRAS CLAVE}

Arte mueble. Flauta. Magdaleniense.

Paleolítico superior.

\section{ABSTRACT}

This paper introduces a bird bone fragment, decorated with lineal incisions. This item, found in the course of the archaeological works developed in the Güelga Cave (Asturias), belongs to de Early Magdalenian period. The paralells point out that this kind of decoration recurs in the Cantabrian Region along this Palaeolithic phase, so it could be a characteristic artwork at this time.

The identification of the item as a flute fragment allows us make some reflections about Palaeolithic musical instruments.

\section{KEY WORDS}

Mobile art. Magdalenian. Flute.

Upper Palaeolithic.

1 Departamento de Prehistoria e Historia Antigua de la UNED. C/ Senda del Rey, s/n; Madrid 28047. mmenendez@geo.uned.es

2 Becario Predoctoral UNED. Departamento de Prehistoria e Historia Antigua de la UNED. C/ Senda del Rey, s/n; Madrid 28047.1.garcia3@cgac.es. 
El hallazgo ocasional de piezas, generalmente en hueso, interpretadas como instrumentos musicales en contextos paleolíticos ha dado lugar a reflexiones sobre su posible función y utilidad. Paralelamente a estas consideraciones se ha tratado de avanzar por hipótesis más ambiciosas, como señalar un posible comienzo documentado de la música y la danza como manifestación sublime del mundo espiritual paleolítico, argumentadas en las dataciones y la pretendida funcionalidad de tales “instrumentos". Nuestro trabajo, con una intención mucho más modesta, se limita a presentar una pieza ósea, asociada a un contexto magdaleniense inferior cantábrico, que puede ser definida como flauta, con interesantes y ajustados paralelos; aunque no podamos sustraernos a realizar algún comentario sobre un tema tan atractivo como dado a la especulación como son estos supuestos instrumentos musicales paleolíticos. Sin duda algunos de ellos debieron producir una calidad y variedad de sonidos escasa y poco matizada; sin embargo, la etnología nos muestra la utilidad de tales instrumentos como sistemas de comunicación, reclamos de caza, utillaje para prácticas chamánicas, etc. Sin olvidar que algunos pudieron utilizarse en el interior de cuevas, con la especial sonoridad que estos recintos confieren a los sonidos más simples.

Algunos autores han hecho clasificaciones de los pretendidos instrumentos musicales paleolíticos (Rubio, 1990, 1992; Schaeffner, 1980; Tranchefort, 1985, etc.), basándose en paralelos etnológicos, en algunas representaciones rupestres paleolíticas y en la interpretación ad hoc de ciertas piezas óseas. En definitiva tales clasificaciones reflejan los tres campos tradicionales del sonido musical: cuerda, percusión y viento. En el primer caso, los instrumentos se habrian confeccionado necesariamente con materias orgánicas como cuero, tendones, fibras vegetales o madera, por lo que no se han conservado restos materiales. Solamente se citan algunas representaciones rupestres que recuerdan tales posibles instrumentos, tal es el caso del famoso brujo de Trois Fréres (lám. 2, fig. 1) que en ocasiones se interpreta como portador de un arco musical, aunque no faltan autores que, en cambio, sugieren que el instrumento que maneja la figura se trataría de una flauta del tipo denominado nasal (Baena et al., 1998; Dauvois, 1989). Esta disparidad de interpretaciones nos puede dar una idea de hasta qué punto nos movemos en el terreno de la subjetividad.

Los instrumentos de percusión ofrecen más posibilidades de identificación, aunque las huellas del golpeteo pueden ser atribuidas a causas muy diversas, ajenas a la música o la mera producción de sonidos. Quizá los ejemplos más conocidos sean los procedentes de yacimientos de la Europa centro-oriental como el conjunto hallado en Mezin (Ucrania) en una cabaña construida con huesos de mamut. Diversos huesos de gran tamaño de este 
animal aparecieron pintados con líneas de ocre y numerosas huellas de percusión insistente. Algunos de ellos, como una escápula y un fémur, producían sonidos que fueron recreados en lo que entonces se denominó como "primera orquesta" (Bibikov, 1975). Además, algunos bastones en forma de $T$ han sido interpretados como bastones de ritmo, al estilo de los usados en las prácticas chamánicas para golpear el tambor. Igualmente se ha aventurado la hipótesis de que los rodetes perforados, tan característicos del Magdaleniense IV, pudieran formar parte de sonajas (Barandiarán, 1976; Rubio, 1990), cuyo entrechoque, previamente ensartadas en un vástago, produciría un sonido rítmico. Desconocemos que estas piezas, que por otra parte parecen evidentes elementos de adorno, hayan proporcionado huellas de uso que apoyen estas hipótesis.

Finalmente, el capítulo de los llamados instrumentos de viento quizá sea el que aporte los ejemplos más claros y numerosos del Paleolítico. Aquellos que se conservan están fabricados en hueso o asta. Destacan la llamadas bramaderas, constituidas por placas de hueso planas y perforadas y con formas generalmente romboidales o lonsángicas (Barandiarán, 1976) que se harian sonar girándolas circularmente en el extremo de una cuerda. Sin embargo, en sentido estricto, los verdaderos instrumentos de viento serían los silbatos y las flautas. Para el Paleolítico, no está muy clara la diferenciación entre ambos, aunque se han adoptado criterios convencionales de morfología y tamaño. En ambos casos el sonido se produce dirigiendo una columna de aire hacia una arista o labio (lám. 1) que la corta y forma remolinos. En correspondencia con la frecuencia de los mismos, se origina lo que en musicología se denomina sonido de corte. En el caso de las flautas, parte del insuflo de aire se dirige hacia el exterior del instrumento y parte al interior, obrando el tubo como resonador.

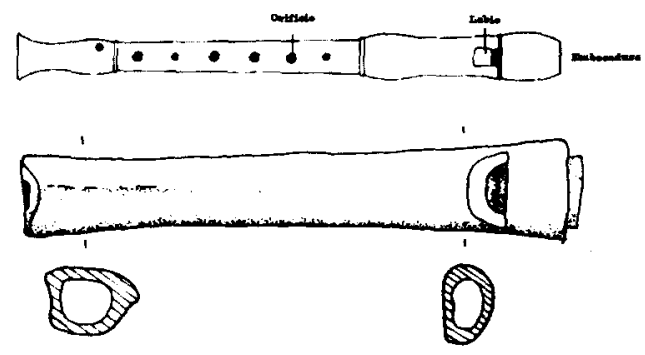

Lámina 1. Flauta dulce actual y reconstrucción experimental de instrumento de viento paleolítico según Baena et al., 1998. 
Los silbatos generalmente se han fabricado sobre una primera o segunda falange de reno (lám. 2, fig. 2 y 3) y, rara vez, sobre falanges de ciervo. Quizá por ello son menos frecuentes en la Península lbérica que en yacimientos franceses. Sin embargo, no es infrecuente que se citen como tales algunos tubos cortos o fragmentos de diáfisis en el Paleolítico superior cantábrico. Los silbatos realizados sobre falanges normalmente presentan una perforación, aunque existe algún ejemplo con dos. El trabajo experimental de M. Dauvois (1983) ha demostrado que en este segundo caso el sonido emitido puede ser modulado por quien insufle el aire, algo imposible en los silbatos de una sola perforación sin el auxilio de un elemento que se sitúe a modo de émbolo en el extremo de salida del aire. Mas allá de la emisión de señales acústicas, desconocemos su uso, aunque las tres alternativas más sensatas son suponer que fueran reclamos de caza, emisores de señales de localización/comunicación o verdaderos instrumentos musicales.

El capítulo de las flautas es, sin duda, el más numeroso y espectacular. Existen multitud de fragmentos de hueso a los que se ha atribuido este uso, aunque no pueda asegurarse con certeza. En otros casos, más afortunados, el instrumento se ha conservado completo, lo que no sólo permite afirmaciones categóricas sobre su utilidad, sino que facilita establecer paralelos con otras piezas incompletas de morfología similar o alguna de sus partes. Además, algunas flautas han aparecido en contextos especiales. Tal es el caso de la cabaña de Dolni Vestonice, donde pudieron celebrarse ritos de contenido mágico-religioso (Klima, 1989), a tenor de las características de los restantes objetos asociados, entre los que se incluye un conjunto numeroso de figuras femeninas en barro cocido y morfología coincidente con las denominadas Venus.

La tipología de las flautas es diversa. Como ya se ha dicho, generalmente están realizadas sobre material óseo. Los huesos más empleados son aquellos largos procedentes de la anatomía de aves de gran envergadura, que también se han interpretado como estuches para agujas, tubos para soplar colorantes $u$ otros productos o mangos de instrumental compuesto desde el Solutrense. Las flautas que se conservan casi enteras nos indican una gran variedad de tipos. Así aparecen con una sola perforación proximal cercana a la embocadura que haría las veces de labio, dos perforaciones próximas a ambos extremos, o varias perforaciones en una cara $u$ opuestas en la superficie del cilindro óseo. Naturalmente no todas ofrecen las mismas posibilidades a la hora de modular el sonido.

Otros tubos de hueso que no presentan perforación han sido igualmente interpretados como flautas. Formarian parte de instrumentos com- 
puestos, unidos entre sí con correas, a modo de flautas de Pan, siringas o policálamos. Algunos, como el tubo de Torre (Guipúzcoa), presentan decoraciones grabadas muy elaboradas.

Existe un tipo de flauta que aquí nos interesa particularmente. Son aquellas que se han realizado sobre un tubo óseo, generalmente de ave, con una única perforación a modo de labio cercana a la embocadura -al menos en los ejemplares conservados, todos ellos fragmentarios- y con una decoración lineal específica. Consiste ésta en series de trazos paralelos en superficies opuestas del cilindro óseo. En el contexto cantábrico
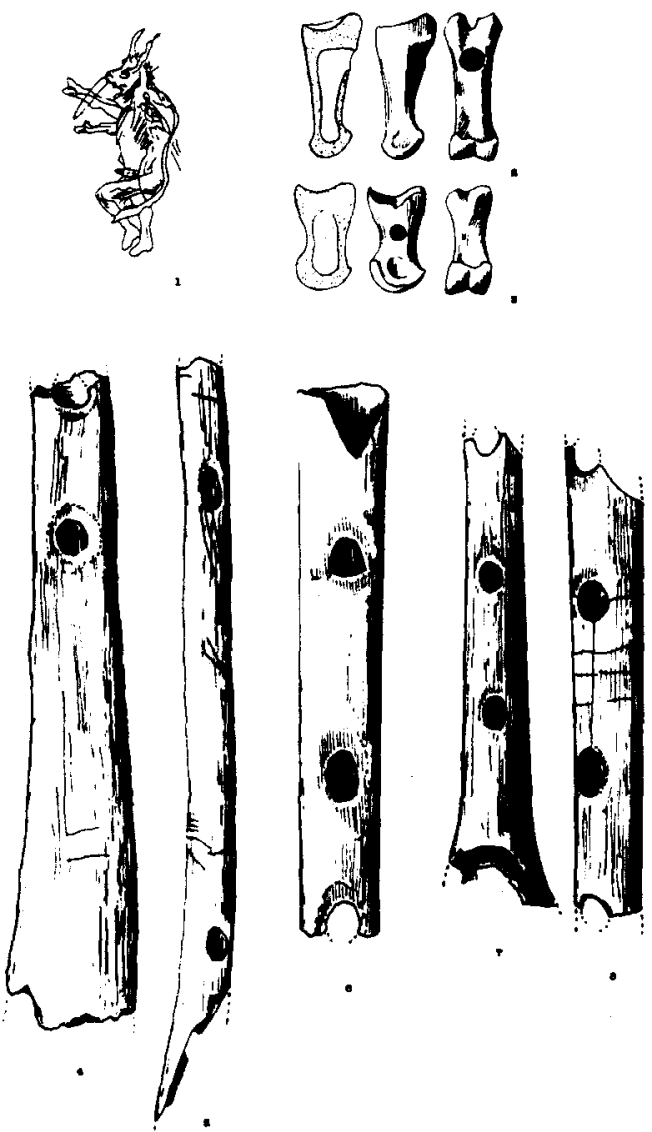

Lámina 2. 1.: representación de Les Trois Frères conocida como «Brujo»; 2.: silbato en primera falange de reno; 3.: silbato en segunda falange de reno; 4, 6-8: Istruritz,

Perigordiense superior; 5.: Isturitz, Auriñaciense. 
se pueden citar dos ejemplares del nivel 8 de la Cueva del Castillo, un

ejemolar del nivel 4b de la Cueva del Rascaño $v$ otro del nivel 8 de la Cueva de la Paloma. A ellos debemos añadir la pieza que presentamos, procedente del nivel 3c de la Cueva de la Güelga. Todos ellos tienen en común una morfología similar, idéntica decoración y una misma cronología, como veremos, por lo que pudieran constituir un tipo específico o característico del Magdaleniense inferior cantábrico.

La cronología de las flautas paleolíticas es diversa. Se han localizado a lo largo de toda la secuencia del Paleolítico superior, desde el Auriñaciense y Gravetiense hasta el Magdaleniense final. No obstante, en los últimos tiempos se ha producido una interesante polémica en torno a la posible consideración como flauta de un fémur de oso de las cavernas con perforaciones, procedente de la ocupación del Paleolítico medio del yacimiento esloveno de Divje Babe I (Turk, 1997), concretamente del nivel 8, datado en $43.100 \pm 700 \mathrm{BP}$. (Nelson, 1997). Su reconstrucción reconoce la posibilidad de que emitiera los sonidos propios de las siete notas de la escala tonal (Fink, 1996). Sin enbargo, se ha puesto en duda que tal pieza sea un verdadero instrumento musical (D'Errico et al., 1998), al plantearse que los agujeros que presenta dicho hueso son más bien resultado de mordeduras de carnívoros. Ambas cosas pudieron compatibilizarse (Chase y Nowell, 1998), pues las posibilidades de emisión de sonidos son tan reales como la acción de los carnívoros, muy probablemente lobos, en la perforación del hueso.

Las primeras flautas indudables aparecen en momentos muy tempranos del Paleolítico superior inicial, como las documentadas en Isturitz (lám. 2, figs. 4 a 8) (Buisson, 1991) o en el yacimiento alemán de Geissenklösterle (Hahn 1996); si bien ya se habían citado silbatos en niveles del musteriense de La Quina (Dauvois, 1983), datados en torno a 60.0000 BP., o en Lezetxiki; pero su naturaleza presenta incertidumbres parecidas a las planteadas en torno al caso de Divje Babe I (Chase 1990). No obstante, la mayoría de los ejemplos escasos de flautas conocidos en el Paleolítico se asignan al Magdaleniense. Parece que su profusión en estos momentos ha de ponerse en relación con el aumento que también experimentan otros objetos utilitarios y artísticos fabricados en hueso y asta.

\section{LA FLAUTA MAGDALENIENSE DE LA GÜELGA}

La Cueva de la Güelga se localiza en la zona centro-oriental de Asturias, concretamente en la cuenca media del río Sella, en las proximidades de Cangas de Onís. Las excavaciones realizadas desde 1989 han 
sacado a la luz la evidencia material de diversas ocupaciones solutrenses

y magdalenienses, distribuidas en diferentes áreas (Menéndez y Martínez, 1992). En la zona A, el nivel 3 ha sido dividido en tres unidades, sıendo lá inferior, denominada 3c, la que ha aportado el volumen de industria y de restos de fauna más notable. La industria lítica se caracteriza por la abundancia de raspadores, siendo muy frecuentes los nucleiformes; un alto grupo auriñaciense, con numerosas hojitas de dorso -en torno al $50 \%$ y abundantes buriles, fundamentalmente diedros. Las azagayas son igualmente numerosas, habiéndose recogido cuarenta ejemplares de diferentes tipos, destacando las de sección cuadrangular y triangular con acanaladuras profundas, así como las circulares de bisel largo, de las que se han localizado varios ejemplares completos de excelente factura. Igualmente se han hallado numerosas varillas semicilíndricas, espátulas, agujas y punzones. El registro arqueológico de la Güelga ofrece, en definitiva, un repertorio óseo amplio, variado y denso si tenemos en cuenta la superficie excavada. Tres dataciones de $\mathrm{C} 14$ sobre hueso sitúan este nivel entre 14.170 y $14.020 \mathrm{BP}$.

En la zona $C$, pueden asignarse al Magdaleniense inferior los niveles 2 y 3, con una industria similar, y una fecha de $\mathrm{C} 14$ para el nivel 2B de $13.890 \pm 130 \mathrm{BP}$. Por tanto, $y$ como ya hemos argumentado en anteriores publicaciones, parece que estas ocupaciones deben situarse en el tramo final del Magdaleniense inferior cantábrico, facies Juyo, con claros paralelos industriales y cronológicos en Paloma 8, Cueto de la Mina D, Cierro 3, Rascaño 4, y sobre todo en el nivel 4 de la Cueva del Juyo (Barandiarán et al., 1985; Utrilla 1981).

El Magdaleniense inferior de la Cueva de la Güelga, ha proporcionado un conjunto de arte mueble extraordinario (Menéndez, 1997; Menéndez y García, e.p.). Aquí queremos dar a conocer una flauta del nivel $3 \mathrm{c}$ de la zona A, presentada con otras piezas en el XXIV Congreso Nacional de Arqueología, celebrado en Cartagena en 1997, pero inédito aún. Anticipamos su estudio al hilo de las reflexiones anteriores sobre instrumentos musicales paleolíticos.

\section{DESCRIPCIÓN Y PARALELOS}

La flauta (lám. 3, fig. 1), con paralelos morfológicos aproximados en dos piezas procedentes del yacimiento francés de Le Roc de Marcamp (lám. 3, figs. 2 y 3), está realizada sobre un fragmento de hueso de ave en forma de tubo, de $44 \times 11 \times 10 \mathrm{~mm}$. Apareció rota en sentido longitudinal en multitud de fragmentos, siendo reconocible como tal tras una 
extraordinaria restauración realizada por Antonio del Rey en el Instituto de Conservación y Restauración de Bienes Culturales. Toda su superficie muestra un deterioro tafonómico intenso, especialmente aquella correspondiente al lateral izquierdo. Este desgaste ha eliminado casi por completo la decoración que en su día cubría dicha cara, de la que apenas pueden apreciarse cinco trazos. Anverso, lateral derecho y reverso de la pieza ofrecen al observador una decoración lineal compuesta por incisiones rítmicas muy profundas, casi excisiones, dispuestas transversalmente al eje longitudinal de la pieza. La erosión y las fracturas han respetado dieciséis trazos en el caso de la cara superior, dieciocho en el del lado derecho y quince en el de la cara inferior. La embocadura está rota, pero muestra una perforación realizada en bisel, a modo de lo que en las flautas actuales se denomina labio (lám. 1), similar a la de otras flautas paleolíticas ya citadas (lám. 3, figs. 2 y 3 ).

Los paralelos son más numerosos de lo que en principio podría pensarse (Delluc, 1987; Cremades,1994). Así encontramos huesos de ave grabados de forma similar en Gourdam, Le Placard, etc., siempre fragmentarios; pero algunos yacimientos como Isturitz, La Garenne, o Placard (lám. 3, fig. 4), han proporcionado ejemplares de flautas completas que presentan una única perforación cercana a la embocadura, similar al tubo decorado de la Güelga. Esta forma y decoración coincide con algunas piezas ya citadas en el Paleolítico cantábrico. Es el caso del tubo perforado y decorado con incisiones del nivel 8 de la Cueva del Castillo (lám. 3, fig. 5), Magdaleniense inferior; al mismo nivel debe asignarse otro tubo con idéntica decoración (lám. 3, fig. 6), aunque no conserva la perforación, si es que la tuvo (Cabrera, 1984). Idéntico caso es el del tubo de la cueva del Rascaño (lám. 3, fig. 7), perteneciente al nivel 4b, Magdaleniense inferior (González Echegaray y Barandiarán, 1981); o al nivel 8, igualmente Magdaleniense inferior, de la Cueva de la Paloma (Corchón, 1994), con una pieza de similares caracteristicas.

De lo anterior parece deducirse que también en el Paleolítico cantábrico se documentan algunos ejemplos de flautas, aunque su valoración en el contexto mobiliar haya sido escasa. Iguaimente, los ejemplares claramente asignables a esta función se concentran en el Magdaleniense inferior y reciben decoraciones formadas por series lineales perpendiculares al eje longitudinal del tubo soporte. Los ejemplares anteriores, como las piezas auriñacienses y perigordienses de Isturitz (lám. 2, figs. 4 a 8) o Pair-non-Pair, no presentan decoraciones, o consisten en algunas lineas sueltas, sin la disposición vista en las flautas del Magdaleniense inferior. Igualmente los ejemplares del Magdaleniense 
medio y superior (Placard, Saint Marcel, Le Roc de Marcamp, etc.) presentan decoraciones mucho más complejas y elaboradas, con un diferente sentido del ritmo, la composición y la simetría. Lo mismo puede decirse de los tubos no perforados, que han sido propuestos como componentes de posibles instrumentos policálamos o flautas de Pan, portadores de complejas decoraciones.

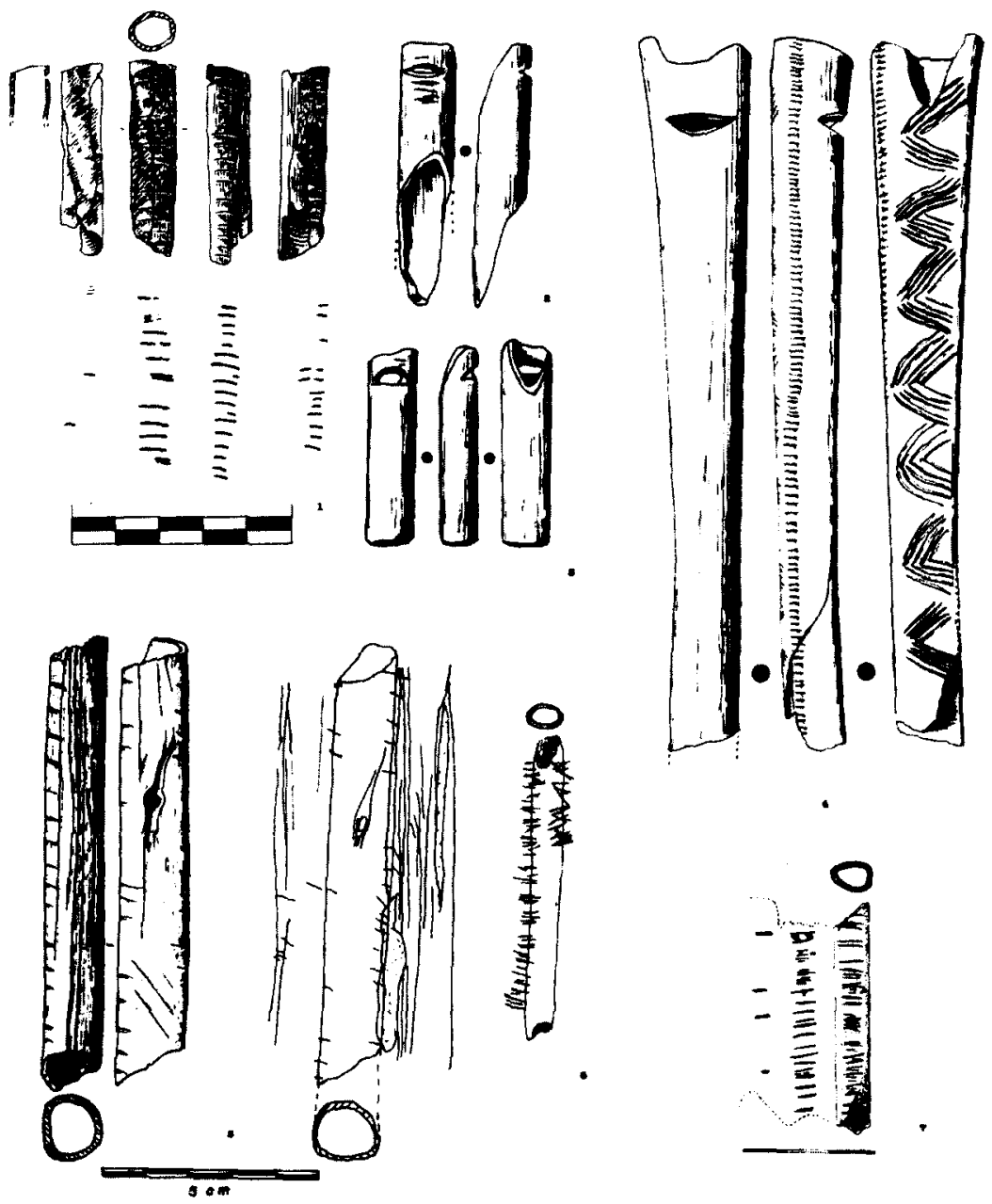

Lámina 3. 1.: La Güelga, nivel 3c; 2-3: Le Roc-de-Marcamp, Magdaleniense superior; 4.: Le Placard, Magdaleniense medio; 5-6.: El Castillo, nivel 8; Magdaleniense inferior; 7.: El Rascaño, nivel 4b, Magdaleniense inferior. 


\section{CONCLUSIONES}

El tubo de hueso de ave decorado que presentamos, roto por ambos extremos, constituye el fragmento de una flauta paleolítica asignable a un momento tardío del Magdaleniense inferior cantábrico, facies Juyo. La decoración de trazos simples formando series longitudinales se revela como característica de este tipo de piezas y reiterada en los ejemplares conocidos del mismo periodo en el cantábrico. Como el volumen de piezas es muy escaso, parece abusivo configurar un tipo con valor cronológico. Sin embargo, es indudable que constituye una coincidencia significativa. De esta manera puede configurarse como hipótesis a contrastar en futuros hallazgos y en un análisis más exhaustivo de similares restos óseos decorados datados en el Paleolítico cantábrico.

\section{BIBLIOGRAFÍA}

Baena, J., Casarrubios, C., Rubio, I. (1998): Etnoarqueología y Música: flautas y silbatos primitivos. Revista de Musicología, XX,2. págs. 1-8. Madrid.

BarandiaRÁN, I. (1967): El Paleomesolítico del Pirineo Occidental. Zaragoza.

BARANDIARÁN, I. (1973): Arte mueble del Paleolítico cantábrico. Zaragoza.

Barandiarán, I. (1976): El Paleomesolítico del Pirineo occidental. Bases para una sistematización tipológica del material óseo paleolítico. Zaragoza.

Barandiarán, I. (1994): Arte mueble del Paleolítico cantábrico: una visión de síntesis en 1994. En Chapa y Menéndez, eds.: 45-79.

Barandiará, I.; Freeman, L.G.; González Echegaray, J. y Klein, R.G. (1985): Excavaciones en Cueva del Juyo; Centro de Investigación y Museo de Altamira, Monografías 14, Santander.

Bibikov, S.N. (1975): Una orquesta de la Edad de Piedra; El Correo de la Unesco, Junio 1975: 28-31.

BuISSON, D. (1991): Les flûtes paléolithics d'Isturitz (Pyrénées atlantiques); Bulletin de la Sociéte Préhitorique Française, 87: 420-433.

Cabrera Valdés, V. (1984): El yacimiento de la Cueva del Castillo (Puente Viesgo, Santander). Bibliotheca Praehistorica Hispana, 22, CSIC. Madrid.

Chapa, T. y Menéndez, M. (eds.) (1994): Arte Paleolítico. Complutum, 5. Madrid.

CHASE, P.G. (1990): Sifflets du Paléolithique moyen (?). Les implications d'un coprolithe de coyote actuel; Bulletin de la Societé Préhistorique Française, 87: 165-167.

CHASE, P.G. y NoweLL, A. (1988): Taphonomy of a sugested Middle Paleolithic Bone Flute from Slovenia; Current Anthropology, 39 (4): 549-553.

CORChÓN, Ma.S. (1986): El arte mueble paleolitico cantábrico: Contexto y análisis interno. Centro de Investigación y Museo de Altamira. Monografía n. ${ }^{\circledR} 16$. M. ${ }^{\circ}$ Cultura.

Cremades, M. (1994): Oeuvres d'art mobilier inédites de la Madelaine (Tursac, Dordogne). PALEO, 6, 233-246.

Dauvors, M. (1983): Son et musique paléolithiques. En La Musique dans l'Antiquité, Les Dossiers de l'Archeologíe, 142, págs. 2-11. París.

DelLuc, B. y G. (1987): Le décor des objets utilitaires du paléolithique supérieur. En L'Art des objets au paléolithique. T.II, 39-72. Foix-Le Mas d'Azil.

D'errico, F.; VILLA, P.; PINTo, A. y RuIz, R. (1998): A Middle Palaeolithic origin of music? Using cave-bear accumulations yo assess the Divje Babe I bone uflute"; Antiquity, 72 (275): 65-79.

FAGES, G. y MOURER-Chauviá, C. (1983): La flûte en os d'oiseau de la grotte sepulcrale de Veyreau (Aveyron) et inventaire des flûtes préhistoriques d'Europe. En La Faune et L'Homme prehistorique: dix études en hommage à Jean Bouchoud. Memoires de la Societé Préhistorique Française: 95-103. 
FINK, B. (1996): Neanderthl flute. Oldest musical instrumen's 4 notes matches 4 of Do, Re, Mi, scale. Musicological analysis; $h$ ttp://www.webster.sk.ca/greenwich/fl-compl.htm

Gonzalez Echegaray, J. y Barandiaran, I. (1981): El Paleolítico Superior de la Cueva del Rascaño (Santander). Centro de Investigación y Museo de Altamira, Monografías 3, Santander.

HAHN, J. (1996): Le Paléolithique supérieur en Allemagne meridionale (1991-1995), en M. OTTE, ed.: $181-186$.

Hoyos Gómez, M.; Martínez Navarrete, M.² I.; Chapa Brunet, T.; Castaños, P. y F.B. Sanchiz (1980): La Cueva de la Paloma. Excavaciones Arqueológicas en España, 116. Madrid.

KLIMA, B. (1989): El arte gravetiense, en VV. AA.: 36-43.

MENÉNDEZ, M. (1997): Historiografía y novedades en el arte mueble paleolítico de la Península Ibérica; Espacio Tiempo y Forma. Serie I, vol. X. UNED. Madrid.

MENÉnDEZ, M. y GarCIA, E. (e. p.): La Cueva de la Güelga (Asturias): arte mueble y territorialidad en el Magdaleniense cantábrico; XXIV Congreso Nacional de Arqueología. Cartagena, 28-31 de octubre 1997.

MENENDEZ, M. y MARTínez, A. (1991-92): Una tibia con ciervas grabadas de la Cueva de la Güelga. Cangas de Onís. Asturias. Zephyrus, XLIV-XLV. Salamanca.

MENENDEZ, M. y MARTÍNEZ, A. (1992): Excavaciones arqueológicas en la Cueva de la Güelga. Campañas de 1989-1990. Excavaciones Arqueológicas en Asturias, 1987-1990. Consejería de Educación y Cultura. Oviedo.

NELSON, D. E. (1997): "Radiocarbon dating of bone and charcoal from Divje Babe I cave", en TURK, ed.: 51-64.

OTTE, M., ed. (1996): Le Paléolithique supérieur européen. Bilan quinquennal (1991-196), ERAUL, 76, Forli.

RuBio, I. (1990): Los instrumentos musicales de la prehistoria: el Paelolítico (I); Boletín de la Asociación Española de Amigos de la Arqueología, 29: 13-19.

Rubi, I. (1992): Los instrumentos musicales de la prehistoria: el Paelolítico (II); Boletín de la Asociación Española de Amigos de la Arqueología, 32: 2-11.

SCHAEFFNER, A. (1980): Origine des instruments de musique; Mouton, La Haya.

TrANCHEFORT, F.R. (1985): Los instrumentos musicales en el mundo; Alianza Música, Madrid.

TuRk, A., ed. (1997): Mousterian bone flute and others finds from Divje Babe I cave site in Slovenia; Institut za Archaeologijo, Ljubljana.

UtriLla, P. (1981): El Magdaleniense Inferior y Medio en la Costa Cantábrica. Centro de Investigación y Museo de Altamira, Memoria 4.

UtriLLA, P. (1987): Bases objectives de la chronologie de l'art mobilier paléolithique sur la côte cantabrique. En L'Art des objets au paléolithique. T.I, 87-99. Foix-Le Mas d'Azil.

VV. AA. (1989): Los comienzos del arte en Europa Central. Museo Arqueológico Nacional, Madrid. 